\title{
Development of a cranium-infection rat model for artificial bone implantation
}

\author{
Yoshikazu Inoue $^{1}$, Yoshiaki Sakamoto ${ }^{2 *}$, Hiroko Ochiai $^{3}$, Yohko Yoshimura ${ }^{1}$ and Takayuki Okumoto ${ }^{1}$ \\ ${ }^{1}$ Department of Plastic and Reconstructive Surgery, Fujita Health University School of Medicine, Japan \\ ${ }^{2}$ Department of Plastic and Reconstructive Surgery, Keio University School of Medicine, Japan \\ ${ }^{3}$ Department of Plastic and Reconstructive Surgery, National Hospital Organization Tokyo Medical Center, Japan
}

\begin{abstract}
For the development of infection-resistant artificial bone, a robust animal model that closely mimics clinical infection is necessary. Therefore, we established a rat model of cranial infection. After creating a bone defect in the parietal cranium of rats, either collagen sponge honeycomb or sterile cotton gauze was inserted into the defect, and wounds were then inoculated with Staphylococcus aureus. This method effectively resulted in cranial infection in a manner dependent on the inserted sponge/gauze. In conclusion, we believe this model will be useful as a cranial infection model and will enable studies of materials used in cranioplasty for their infection potential in a state befitting that of a clinical setting.
\end{abstract}

\section{Introduction}

Plastic surgeons often encounter situations in which cranioplasty involving artificial materials is performed in patients with cranial defects following neurosurgery or external injury. Recent developments in medical engineering have introduced various types of artificial bone to the market [1-10], and these materials are becoming more frequently and widely used. However, among serious complications is infection. Occurrence of infection deteriorates the prognosis as artificial implantsoften support bacterial growth,compromising the efficacy of the antibiotic treatment; in fact, some cases require extraction of the artificial bone. If infected artificial materials are not removed, the infection may spread to a wider area and cause intractable skin ulceration, requiring not only removal of the artificial bone but also reconstruction of the damaged skin and leading to a protracted hospitalization $[11,12]$. To expedite the development of infectionresistant artificial bone, a robust animal model that closely mimics clinical infection is necessary [13]. Infection models of crush wounds [14], burn wounds [15], and ulceration caused by the insertion of foreign materials such as suture threads or sand have been developed [16], but, to our knowledge, there is currently no established cranial infection model. Small animals such as rats are generally considered to possess a strong resistance to infection, and it has been considered highly challenging to maintain infection in these animal models [17]. In this study, we investigated the development of a rat model of cranial infection that can be maintained in an infected state.

\section{Materials and methods}

\section{Experimental methods}

Thirty Sprague-Dawley adult male rats (SD rats; obtained from Japan SLC, Inc., Shizuoka, Japan), aged 10-12 weeks and weighing 390-432 g, were used as the experimental model. First, rats were anesthetized by intraperitoneal administration of $0.4 \mathrm{ml}$ pentobarbital. The top of the head was shaved to expose the skin which was then disinfected with ethanol. A 2-cm sagittal skin incision was made through the midline of the head using a \#15 scalpel, and the parietal skull under the periosteum was exposed. Next, a defect in the full thickness of the bone, measuring $5 \mathrm{~mm}$ in diameter, was created on each side while avoiding the saggital suture (Figure 1).

Two types of foreign materials were evaluated for use in the model; either a collagen sponge honeycomb (AteloCell ${ }^{\mathbb{B}}$; Koken Co., Ltd., Tokyo, Japan) or sterile cotton gauze was inserted into the bone defects. No foreign material was used in the control group. To create infection, 15-CFU Staphylococcus aureus (S. aureus, $30 \mathrm{CFU} / \mathrm{cell}$; Easy QA Ball ${ }^{\circledR}$; Nissui Pharmaceutical Co., Ltd., Tokyo, Japan) were inoculated into each of the bone defects, while a control group was not inoculated with the bacteria. Wounds were then sutured and closed with 4-0 nylon thread; wounds were not drained via methods such as external ointment or gauze covering.

Based on inoculation of bacteria and the insertion of foreign materials, rats were divided into six groups as follows.

Group 1: no materials \& no S. aureus,

Group 2: no materials \& S. aureus,

Group 3: sponge \& no S. aureus,

Group 4: sponge \& S. aureus,

Group 5: gauze \& no S. aureus,

Correspondence to: Yoshiaki Sakamoto, Department of Plastic and Reconstructive Surgery, Keio University School of Medicine, 35 Shinanomachi, Shinjuku-ward, Tokyo 160-8582, Japan, Tel: +81-3-5363-3814, Fax: +81-3-33521054; E-mail: ysakamoto@z8.keio.jp

Key words: artificial bone, cranioplasty, cranial infection model, rat model

Received: February 19, 2016; Accepted: March 04, 2016; Published: March 08, 2016 


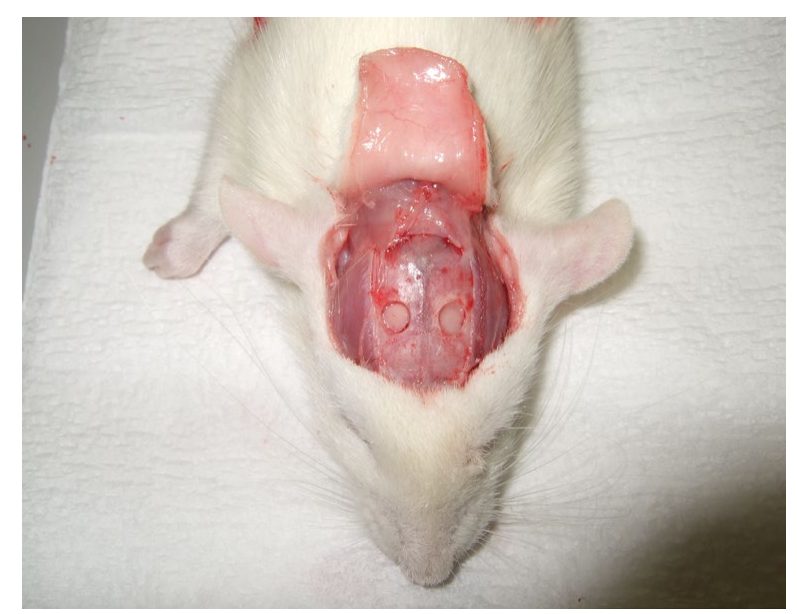

Figure 1. Creation of the bone defects at the cranium of the experimental model.

\section{Group 6: gauze \& S. aureus.}

Thus, there were a total of six groups with six bone defects each; three bone defects were examined 3 days after surgery, whereas the other three were examined 7 days after for each group.

All animal experiments were performed in accordance with protocols approved by the experimental animal committee at Fujita Health University

\section{Bacterial analysis using gram staining}

At 3 and 7 days after surgery, rats were anesthetized via intraperitoneal administration of $0.4 \mathrm{ml}$ pentobarbital. The calvarias were dissected, and the granulation status of the bone defects, including the presence of exudate and abscess formation, was visually evaluated. Granulation tissues were collected from the cranial defects of the rats in each group and fixed in $4 \%$ PFA (paraformaldehyde) before being embedded in paraffin. The specimens were sectioned in the coronal plane at 5- $\mu \mathrm{m}$ thickness and Gram-stained for observation under a conventional qualitative, bright-field light microscope, where they were assessed for the presence of Gram-positive bacteria.

\section{Evaluation of increased bacterial counts using bacterial culture}

At 3 and 7 days after surgery, 2-mm squares of granulation tissue were collected from the centers of the bone defects from rats in each group. They were then mashed and dissolved in $1 \mathrm{ml}$ physiological saline solution; $0.1 \mathrm{ml}$ solution was subsequently inoculated and smeared on to mannitol salt agar with egg yolk. Each agar plate was then placed in an incubator $\left(37^{\circ} \mathrm{C}, 5 \% \mathrm{CO}_{2}\right)$ for $24 \mathrm{hr}$, and the number of colonies was then counted.

\section{Statistical analysis}

Statistical analysis was performed using the Wilcoxon signedrank test. All calculations were performed using SPSS version 17 for Windows (SPSS Inc., Chicago, IL, USA), and $p$ values $<0.05$ were considered statistically significant.

\section{Results}

\section{Macroscopic appearance}

A little abnormal granulomatous tissue was observed in Groups 3 and 5 . There was significant leachate and both thick and weak abnormal granulation tissue observed in all wounds inoculated with $S$. aureus (Groups 2, 4, and 6). There was no significant difference in appearance by comparing the specimen on days 3 and 7 .

\section{Histology}

In the histologic analysis of wounds 3 days after surgery, no Grampositive bacteria were detected in the tissues from Groups 1, 3, and 5, which were the groups not infected with S. aureus (Figure 2). As expected, disseminated Gram-positive bacteria were sporadically detected in tissues from Groups 2, 4, and 6.

Seven days after surgery, no Gram-positive bacteria were detected in the tissues from any of the groups of uninoculated rats (Groups 1, 3, and 5). In addition, Gram-positive bacterial colonies were not observed in Group 2 (Figure 3). This was different from the results obtained 3 days after surgery. On the other hand, Gram-positive bacteria were observed in the tissues from Groups 4 and 6, seven days after surgery. When compared with Group2 that showed no colony, this result demonstrates the importance of the foreign materials for the bacterial growth.

\section{Bacterial counts}

The number of Gram-positive bacterial colonies was counted from specimens after 24 hour of bacterial culture. In samples from 3 days after surgery, no colonies were counted in Groups 1,3, and 5. Among the bacteria inoculated into Groups 2, 4, and 6, the mean measured colony counts were $210 \pm 46.3,747 \pm 85.2$, and $946 \pm 109.5$, respectively. There were significant differences in colony counts between Groups 1 and 2, Groups 1 and 4, and Groups 1 and $6(\mathrm{p}<0.01)$. Furthermore, there were significant differences in colony counts between Groups 2
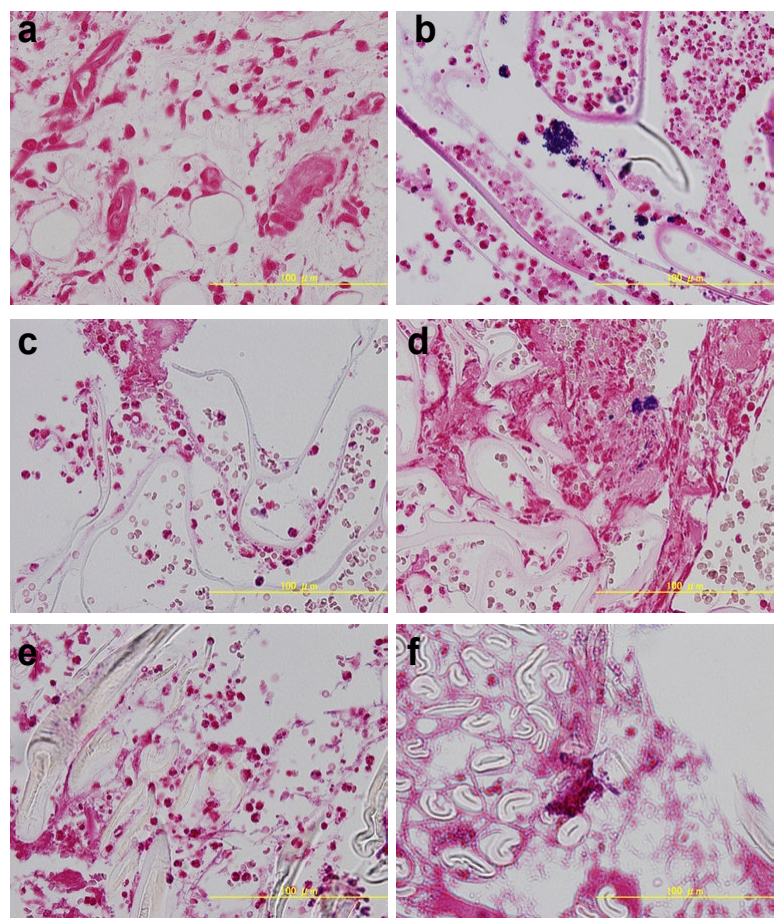

Figure 2. Histological macroscopic appearance 3 days after surgery (Gram staining). No Gram-positive bacteria were detected in Groups 1, 3, and 5. Disseminated Gram-positive bacteria were instead sporadically detected in samples from Groups 2, 4, and 6 . a. Group 1: no materials \& no S. aureus, b. Group 2: no materials \& S. aureus, c. Group 3: sponge \& no S. aureus, d. Group 4: sponge \& S. aureus, e. Group 5: gauze \& no S. aureus, f. Group 6: gauze \& S. aureus. 

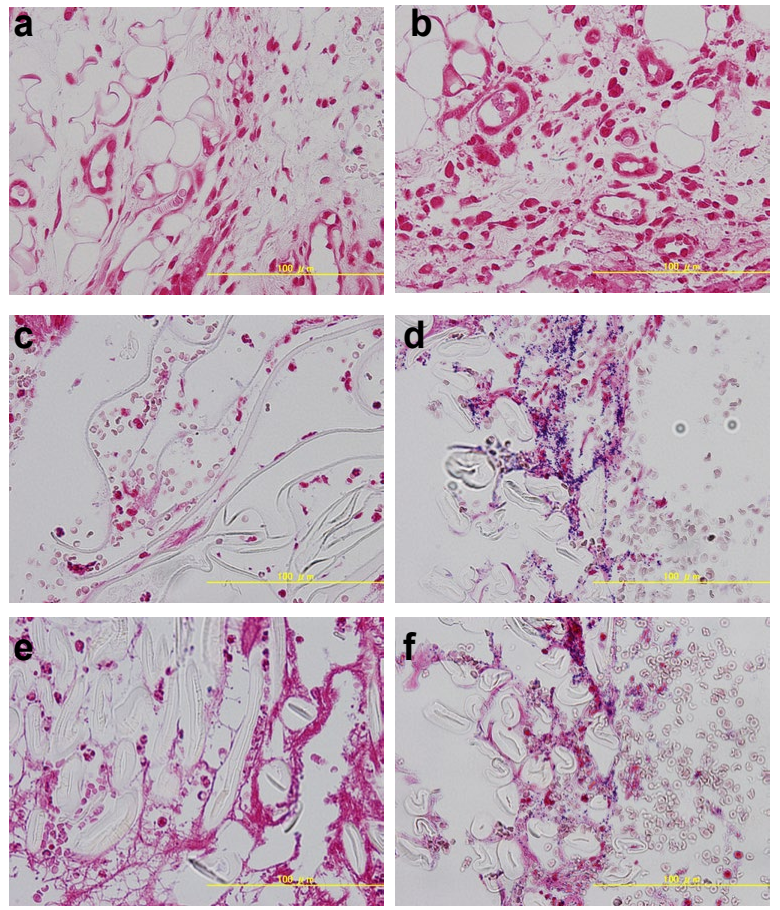

Figure 3. Histological macroscopic appearance 7 days after surgery (Gram staining). No Gram-positive bacteria were detected in groups $1,2,3$, and 5 . The results are markedly different in Group 2 compared with those on 3 days. On the other hand, a lot of Grampositive bacteria were detected in samples from Groups 4 and 6 .

a. Group 1: no materials \& no S. aureus, b. Group 2: no materials \& S. aureus, c. Group 3: sponge \& no S. aureus, d. Group 4: sponge \& S. aureus, e. Group 5: gauze \& no S. aureus, f. Group 6: gauze \& S. aureus.

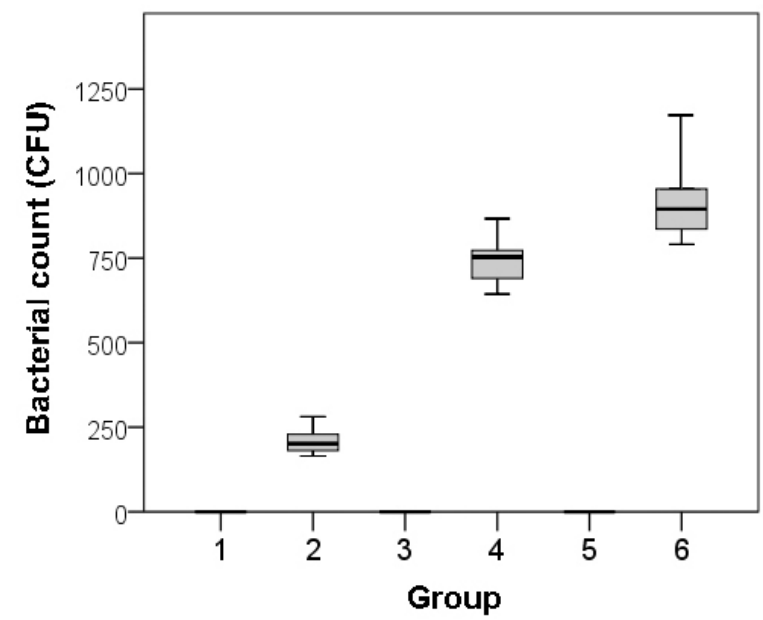

Figure 4. Bacterial colony counts in each group 3 days after surgery.

Group 1: no materials \& no S. aureus, Group 2: no materials \& S. aureus, Group 3: sponge \& no S. aureus, Group 4: sponge \& S. aureus, Group 5: gauze \& no S. aureus, Group 6: gauze \& S. aureus.

and 4 and between Groups 2 and 6 ( $\mathrm{p}<0.01$; Figure 4).

The results with the tissues obtained seven days after surgery showed a trend similar to that with the tissues at three days after surgery. The mean measured colony counts of samples 7 days after surgery, among Groups 1, 3, and 5 were 0 for each group. The mean measured colony counts for Groups 2, 4, and 6 were $12 \pm 8.2,5147 \pm 366.7$, and $5229 \pm$
690.9 , respectively. There were significant differences in colony counts between Groups 2 and 4 and between Groups 2 and $6(p<0.01)$ at 3 days after surgery, signifying the dependency of the bacterial growth on the foreign materials. However, there was no significant difference between Groups 1 and 2 ( $\mathrm{p}=0.52$; Figure 5).

\section{Discussion}

Major skull defects can present as most disturbing deformities. Cranioplasty can restore cerebral protection and improve craniofacial esthetics. When autogenous bone is not available or when its use is inappropriate, alloplastic materials are considered the next best option [6]. Nevertheless, none of the materials currently used to reconstruct skull defects are completely satisfactory. Hydroxyapatite is a biocompatible and osteoconductive material that lacks significant toxic or immunogenic properties; this would seem an ideal substrate for the repair of cranial defects [18].

However, infections present a major complication of cranioplasty procedures and in many cases of post-surgical infection, removal of the implant material becomes a necessity [19]. Once bacteria attach to the implant surface, they can cause localized inflammation and progressively damage neighboring tissues [20]. Furthermore, this may result in replacement failure of the implant material, which can lead to a fatal outcome. We have used artificial bone for cranial defects [21,22], and we now regard the development of artificial bone, which possesses anti-infective and compressive strengths, as a really important matter because of the aforementioned reasons.

Before clinical application of such procedures to confirm the efficacy of the new treatment, animal studies need to be conducted. Rats have a large and thick enough skull to create bone defects and are relatively frequently used for experiments assessing calvarial defects [23]. Therefore, we considered developing a cranium-infected rat model for grafting of an artificial bone. However, it is difficult to develop infection models in rodents, and some studies have created skin infection models using foreign materials [14,17]. We hypothesized that it would be possible to grow pathogenic microbes and induce a tissue reaction in response to using foreign materials in cranial defects, after reading these reports. The collagen sponge (AteloCell ${ }^{\circledR}$ ) used as foreign material was a three-dimensional, honeycomb-shaped, and pepsin-

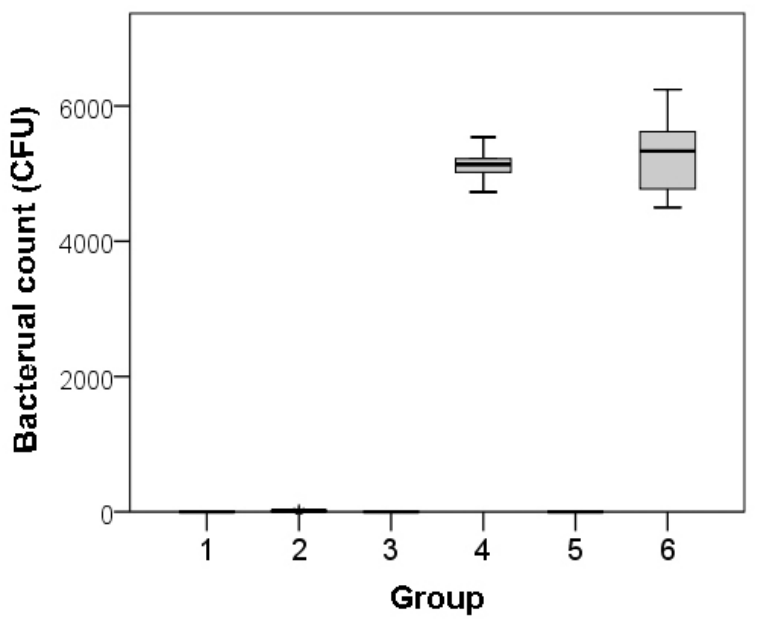

Figure 5. Bacterial colony counts in each group 7 days after surgery.

Group 1: no materials \& no S. aureus, Group 2: no materials \& S. aureus, Group 3: sponge \& no S. aureus, Group 4: sponge \& S. aureus, Group 5: gauze \& no S. aureus, Group 6: gauze \& S. aureus. 
treated material. It has biodegradable properties and is frequently used in various tissue engineering applications $[24,25]$. We chose this material because the composition was similar to biological tissue. In addition, we used a cotton gauze as foreign material, to conform to the experiment reported by Tachi et al. [16]. They developed a model of wound infection in which persistence of infection was achieved for 9 days following ulceration due to the application of gauze to the base of a full-thickness wound.

In the present study, we used S. aureus as a pathogen for cranial infection. This bacterium is commonly found on human fingers, nasal vestibules, and the pharynx. It is also present on the skin and is considered to be a potential inflammatory bacterium in cranial artificial bone infections. Therefore, we used S. aureus to inoculate the cranial defect wounds in this experiment.

We used the bacteria which we gathered from inpatients for the beginning of this experiment. However, there was various bacteria got mixed and it was difficult to control the certain number of the bacteria. Moreover, there was possibility that it might not contain viable cells and result in "zero counts" when used. Therefore we used the Easy QA Ball $^{\circledR}$ (BioBall ${ }^{\circledR}$; as a following now) because of the stabilization and recovery of viable cells, the accurate number of bacteria. In addition, it requires no preparation or pre-incubation, and it can be added directly to media or matrix samples [21]. We got to know through the process, it was difficult to count and compare the number of too many bacterial colonies because the bone defect was very small, so that we determined $15 \mathrm{CFU}$ of S. aureus was appropriate to inoculate.

Our study had certain limitations. We only examined histological granulation tissue of calvarial bone defects. It was difficult to manufacture samples of rat calvarial bone, while not injuring the dura mater and brain. However, we think that it is necessary to use a method, which fully explores the intracranial changes because the clinician is likely to be interested in the connections in this area. In addition, we did not monitor the duration of the infection. The autogenous bone causes a reaction similar to bacterial "melting," but we do not know how the artificial bone changes bacteria. Therefore, it is necessary to control the period of infection when investigating the alteration of artificial bone.

In conclusion, we believe this model will be useful as a cranial infection model and will enable the study of artificial bone used in cranioplasty and their potential for infection in a state more similar to that of a clinical setting.

\section{References}

1. Eppley BL, Kilgo M, Coleman JJ $3^{\text {rd }}$ (2002) Cranial reconstruction with computergenerated hard-tissue replacement patient-matchedimplants: indications, surgical technique, and long-term follow-up. Plast Reconstr Surg 109: 864-871. [Crossref]

2. Roberson JB, Rosenberg WS (1997) Traumatic cranial defects reconstructed with the HTR-PMI cranioplastic implant. J Craniomaxillofac Trauma 3: 8-13. [Crossref]

3. Ono I, Tateshita T, Satou M, Sasaki T, Matsumoto M, et al. (1999) Treatment of large complex cranial bone defects by using hydroxyapatite ceramic implants. Plast Reconstr Surg 104: 339-349. [Crossref]

4. Heissler E, Fischer FS, Bolouri S, Lehmann T, Mathar W, et al. (1998) Custom-made cast titanium implants produced with $\mathrm{CAD} / \mathrm{CAM}$ for the reconstruction of cranium defects. Int J Oral Maxillofac Surg 27: 334-338. [Crossref]

5. Eppley BL, Sadove AM, German RZ (1990) Evaluation of HTR polymer as a craniomaxillofacial graft material. Plast Reconstr Surg 86: 1085-1092. [Crossref]

6. Marchac D, Greensmith A (2008) Long-term experience with methylmethacrylate cranioplasty in craniofacial surgery. J Plast Reconstr Aesthet Surg 61: 744-752. [Crossref]
7. Gosain AK (1997) Hydroxyapatite cement paste cranioplasty for the treatment of temporal hollowing after cranial vault remodeling in a growing child. J Craniofac Surg 8: 506-511. [Crossref]

8. Lew D, Farrell B, Bardach J, Keller J (1997) Repair of craniofacial defects with hydroxyapatite cement. J Oral Maxillofac Surg 55: 1441-1449. [Crossref]

9. Burstein FD, Cohen SR, Hudgins R, Boydston W, Simms C (1999) The use of hydroxyapatite cement in secondary craniofacial reconstruction. Plast Reconstr Surg 104: 1270-1275. [Crossref]

10. Gürbüz MS, Celik O, Berkman MZ (2012) Infection of cranioplasty seen twenty years later. J Korean Neurosurg Soc 52: 498-500. [Crossref]

11. Brett-Major DM, Baraniak SM, Gilhooly JE, Christensen RL, Grant GT, et al. (2008) Foreign-body reaction mimicking postneurosurgical infection after cranioplasty. Mil Med 173: 697-699. [Crossref]

12. Tokoro K, Chiba Y, Tsubone K (1989) Late infection after cranioplasty--review of 14 cases. Neurol Med Chir (Tokyo) 29: 196-201. [Crossref]

13. Stefini R, Esposito G, Zanotti B, Iaccarino C, Fontanella MM, et al. (2013) Use of "custom made" porous hydroxyapatite implants for cranioplasty: postoperative analysis of complications in 1549 patients. Surg Neurol Int 4: 12. [Crossref]

14. Lammers R, Henry C, Howell J (2001) Bacterial counts in experimental, contaminated crush wounds irrigated with various concentrations of cefazolin and penicillin. $\mathrm{Am} J$ Emerg Med 19: 1-5. [Crossref]

15. Felts AG, Giridhar G, Grainger DW, Slunt JB (1999) Efficacy of locally delivered polyclonal immunoglobulin against Pseudomonas aeruginosa infection in a murine burn wound model. Burns 25: 415-423. [Crossref]

16. Tachi M, Hirabayashi S, Yonehara Y, Suzuki Y, Bowler P (2004) Development of an experimental model of infected skin ulcer. Int Wound $J$ 1: 49-55. [Crossref]

17. Stepińska M, Grzybowski J, Struzyna J, Olszowska M, Jabłońska H, et al. (1995) Mouse model of infected wound. Acta Microbiol Pol 44: 39-46. [Crossref]

18. Durham SR, McComb JG, Levy ML (2003) Correction of large ( $>25 \mathrm{~cm}(2))$ cranial defects with "reinforced" hydroxyapatite cement: technique and complications Neurosurgery 52: 842-845. [Crossref]

19. Thomaidis PC, Pantazatou A, Kamariotis S, Vlachos K, Roussos G, et al. (2015) Sonication assisted microbiological diagnosis of implant-related infection caused by Prevotella disiens and Staphylococcus epidermidis in a patient with cranioplasty. BMC Res Notes 17: 307. [Crossref]

20. Dempsey KE, Riggio MP, Lennon A, Hannah VE, Ramage G, et al. (2007) Identification of bacteria on the surface of clinically infected and non-infected prosthetic hip joints removed during revision arthroplasties by $16 \mathrm{~S}$ rRNA gene sequencing and by microbiological culture. Arthritis Res Ther 9: R46. [Crossref]

21. Nakajima T, Yoshimura Y, Nakanishi Y, Kanno T, Sano H, et al. (1995) Anterior crania base reconstruction using a hydroxyapatite-tricalciumphosphate composite (Ceratite) as a bone substitute. J Craniomaxillofac Surg 23: 64-67. [Crossref]

22. Nakajima T, Yoshimura Y, Nakanishi Y, Koga S, Katada K (1995) Integrated life-sized solid model of bone and soft tissue: application for cleft lip and palate infants. Plast Reconstr Surg 96: 1020-1025. [Crossref]

23. Ramalingam S, Al-Rasheed A, ArRejaie A, Nooh N, Al-Kindi M, et al. (2015) Guided bone regeneration in standardized calvarial defects using beta-tricalcium phosphate and collagen membrane: a real-time in vivo micro-computed tomographic experiment in rats. Odontology. [Crossref]

24. Kuboki Y, Iku S, Yoshimoto R, Kaku T, Takita H, et al. (2009) Calcified Honeycombshaped Collagen Maintains its Geometry in Vivo and Effectively Induces Vasculature and Osteogenesis. Nano Biomed 1: 85-94.

25. Lee E, Han SY, Choi HS, Chun B, Hwang B, et al. (2015) Red blood cell generation by three-dimensional aggregate cultivation of late erythroblasts. Tissue Eng Part A 21: 817-828. [Crossref]

Copyright: (C2016 Inoue Y. This is an open-access article distributed under the terms of the Creative Commons Attribution License, which permits unrestricted use, distribution, and reproduction in any medium, provided the original author and source are credited. 